\title{
Antimineralization treatment and patient-prosthesis mismatch are major determinants of the onset and incidence of structural valve degeneration in bioprosthetic heart valves
}

\author{
Willem Flameng, MD, PhD, Filip Rega, MD, PhD, Monique Vercalsteren, RN, Paul Herijgers, MD, PhD, and \\ Bart Meuris, MD, PhD
}

Background: We examined the influence of multiple valve-related parameters on the onset and incidence of valve degeneration in aortic bioprostheses through detailed echocardiographic follow-up.

\begin{abstract}
Methods: In 648 patients (mean age, $73.8 \pm 4.9$ years) receiving an aortic valve bioprosthesis, long-term clinical (mean, $7.5 \pm 3.2$ years) and echocardiographic (mean, $6.5 \pm 3.4$ years) follow-up were performed. The occurrence of signs of structural valve degeneration (stenosis type and regurgitation type) was studied through multivariate analysis, including tissue origin, design and label size of the prosthesis, effective orifice area index (EOAi), patient-prosthesis mismatch (PPM; EOAi $<0.85 \mathrm{~cm}^{2} / \mathrm{m}^{2}$ ), and antimineralization treatment.
\end{abstract}

\begin{abstract}
Results: Structural valve degeneration (SVD) was diagnosed in $12.6 \%$ of patients. In $7.6 \%$, it was of the stenosis type (S-SVD); in 5\%, it was the regurgitation type (R-SVD). The absence of antimineralization treatment is an independent predictor of SVD, S-SVD, and R-SVD. Patient-prosthesis mismatch is an independent predictor of SVD and S-SVD, but not of R-SVD. Patients receiving a nontreated valve show a freedom of SVD at 10 years follow-up of $70.1 \pm 4.3 \%$ versus $90.9 \pm 3.6 \%$ in patients receiving a treated valve $(P<.0001)$. Patients having PPM and receiving a nontreated valve show a freedom of SVD at 10 years of follow-up of only $59.8 \pm$ $7.0 \%$ versus $88.7 \pm 3.6 \%$ in patients also having PPM but receiving a treated valve $(P<.0001)$. In patients not having PPM, the corresponding values were $78.0 \pm 4.3 \%$ and $92.7 \pm 3.4 \%$ for nontreated versus treated valves respectively $(P=.01)$.
\end{abstract}

Conclusions: Antimineralization treatment of bioprosthetic heart valves is effective and reduces the incidence of SVD significantly. Because valve type and size are determined at the moment of implantation, the surgeon carries an important responsibility in protecting the patient from valve degeneration. (J Thorac Cardiovasc Surg 2014;147:1219-24)

In a previous study, we showed that patient-prosthesis mismatch (PPM) is associated with an increased incidence of structural valve degeneration (SVD) in patients receiving a bioprosthetic aortic valve. ${ }^{1}$ Our report on this issue was reviewed critically and it was concluded that we presented compelling evidence that the insertion of a bioprosthesis that is too small in relation to body size is harmful in the long term. ${ }^{2-5}$ However, Yacoub and El-Hamamsy ${ }^{5}$ pointed out in their comment that also other forms of interactions between host and valve, apart from PPM, can cause structural and functional changes. To study the interrelationship between PPM and these confounding factors in the development of SVD, it is necessary to consider a multivariate

\footnotetext{
From Cardiac Surgery, Department of Cardiovascular Diseases, Katholieke Universiteit Leuven, Leuven, Belgium.

Disclosures: Authors have nothing to disclose with regard to commercial support.

Received for publication May 9, 2012; revisions received Dec 15, 2012; accepted for publication March 15, 2013; available ahead of print April 29, 2013.

Address for reprints: Bart Meuris, MD, PhD, Department of Cardiac Surgery, Gasthuisberg, University Hospitals Leuven, Herestraat 49, B-3000 Leuven, Belgium (E-mail: bart.meuris@uzleuven.be).

$0022-5223 / \$ 36.00$

Copyright (C) 2014 by The American Association for Thoracic Surgery

http://dx.doi.org/10.1016/j.jtcvs.2013.03.025
}

approach that has to include not only patient-related factors, but also valve-related factors such as valve design (stented or stentless), origin of the tissue used to construct the valve (porcine aortic valve or bovine pericardium), and anticalcification treatment of the valve. For example, novel strategies to mitigate valve calcification could play a role. Indeed, we know from clinical and experimental work that besides the age of the recipient, the design-related stress distribution on the device, the origin of the tissue and the type of agent used to cross-link this tissue, and the anticalcification treatment used during the preparation of the device are fundamental factors in determining the calcification potential of bioprosthetic valves. ${ }^{6}$ To deal with the variety of these possible factors influencing valve durability, we performed a clinical study that included 8 types of bioprostheses: stented as well as stentless valve types, porcine and pericardial valves, and valves treated with antimineralization technology or not.

\section{METHODS \\ Patient Population \\ A group of 648 patients (mean age, $73.8 \pm 4.9$ years; $52 \%$ males) underwent aortic valve replacement using a bioprosthetic valve. Their}




\section{Abbreviations and Acronyms \\ EOA = effective orifice area \\ $\mathrm{EOAi}=$ effective orifice area index \\ PPM = patient-prosthesis mismatch \\ $\mathrm{R}-\mathrm{SVD}=$ regurgitation-type structural valve degeneration \\ S-SVD $=$ stenotic-type structural valve degeneration \\ SVD = structural valve degeneration}

mean body surface area was $1.78 \pm 0.19 \mathrm{~m}^{2}$. The majority $(94 \%, \mathrm{n}=609)$ had aortic valve stenosis combined eventually with regurgitation, and $6 \%$ $(\mathrm{n}=39)$ had regurgitation exclusively. The mean ejection fraction was $62 \%$, and $87 \%(\mathrm{n}=564)$ was in sinus rhythm, $8 \%(\mathrm{n}=52)$ in atrial fibrillation, and $5 \%(\mathrm{n}=32)$ had pacemaker rhythm. Five percent of the patients $(\mathrm{n}=32)$ were in New York Heart Association functional class I, 48\% $(\mathrm{n}=311)$ in class II, $40 \%(\mathrm{n}=259)$ in class III, and $7 \%(\mathrm{n}=46)$ in class IV. Forty-nine percent of patients $(\mathrm{n}=312)$ received concomitant coronary bypass grafting.

\section{Prosthetic Valve Characteristics}

Specific valve models, design, tissue origin, and tissue treatment are listed in Table 1, together with patient-related variables grouped per valve type. Two types of valve design were used: stented $(n=449$ or $69 \%$ of cases) or stentless $(n=199$ or $31 \%)$ bioprostheses. Median label size was $23 \mathrm{~mm}$ (range, 19-29 mm), for stentless valves it was $25 \mathrm{~mm}$ (range, 19-29 mm), and for stented valves it was $23 \mathrm{~mm}$ (range, 19-29 mm). Two types of biologic material were used: porcine aortic valves $(n=396$ or $61 \%)$ and bovine pericardial tissue $(\mathrm{n}=252$ or $39 \%)$. The valves were either treated with an antimineralization treatment $(n=377$ or $58 \%)$ or had no treatment $(\mathrm{n}=271$ or $42 \%)$.

\section{Patient-Prosthesis Mismatch}

Patient-prosthesis mismatch was calculated using the patients' body surface area and the values of the corresponding reference effective orifice area (EOA) of the used valves according to literature data. ${ }^{7-9}$ PPM was defined as an EOA index (EOAi) $<0.85 \mathrm{~cm}^{2} / \mathrm{m}^{2}$.

\section{Follow-up and Structural Valve Deterioration}

Clinical and echocardiographic follow-up was performed at hospital discharge and thereafter periodically by the referring cardiologist. Survival, reoperation, cerebrovascular accidents, bleeding complications, anticoagulation therapy, New York Heart Association class, and cardiac rhythm were recorded. In this study, echocardiographic findings during follow-up were used to detect early signs of SVD. ${ }^{1}$ Two types of SVD were distinguished: a stenotic type (S-SVD) or a regurgitation type (R-SVD). For every valve model used, the mean value of the peak pressure gradient across the valve at discharge was determined for the patient population receiving this valve model. A cutoff value was then calculated by adding 1 standard deviation to the obtained mean value of the peak pressure gradient of this specific valve model. When, during the follow-up, persisting values of the peak pressure gradient above this cutoff occurred, the diagnosis of S-SVD was made. In none of the patients, regardless of the valve model, was a valvular regurgitation score $>1 / 4$ found at discharge. Therefore, a patient developing a valvular regurgitation of a degree $>1 / 4$ during follow-up, was diagnosed as having R-SVD. Patients developing a combination of valve stenosis and regurgitation were classified as having S-SVD. For the analysis of SVD, we obviously excluded the in-hospital deaths $(n=37)$ and patients with insufficient echocardiographic follow-up $(\mathrm{n}=31)$, resulting in a population of 580 patients with long-term clinical and echocardiographic follow-up.

\section{Statistical Analysis}

For the formulation of valve-related complications, standard guidelines and definitions of terms were used according to recently published recommendations. ${ }^{10}$ Univariate testing for comparisons between groups was performed using nonparametric tests (Kruskal-Wallis, Mann-Whitney, and Wilcoxon). Overall survival and freedom from SVD were visualized using Kaplan-Meier curves. Log-rank testing was used for comparison between 2 groups. Further analysis included standard single predictor and multivariable $(P<.1$ threshold to enter the model $)$ Cox proportional hazards models. The following variables were analyzed: (1) patient-related variables such as age, gender, need for concomitant bypass grafting, treated diabetes mellitus, hypercholesterolemia, arterial hypertension, obesity (body mass index $>30$ ), statin use, and presence of metabolic syndrome (at least 3 of the previous 5 factors present); and (2) valve-related variables, including labeled size, type, design (stented or stentless), tissue origin (porcine or pericardial), presence of anticalcification treatment, EOAi, and PPM. $P<.05$ was considered statistically significant for the study.

\section{RESULTS \\ Follow-up}

Follow-up was $98 \%$ complete (12 patients were lost to follow-up). The median follow-up period was 7.7 years (mean, $7.5 \pm 3.2$ years), with a maximum of 15.6 years. Implant and follow-up periods for the different valve models are given in Table 1. Considering length of follow-up, there are no significant differences between the subgroups $(P=.15)$. Echocardiography was performed in $95.3 \%$ of the hospital survivors. In total, 2990 echo reports were collected (mean, 4.6 echo reports per patient). In $61 \%$ of the patients, the last echocardiography was recorded within the last year of clinical follow-up, and in $79 \%$ was within the last 3 years. We reached a median echocardiographic follow-up of 7.0 years (mean, $6.5 \pm 3.4$ years).

\section{Clinical Outcome}

Hospital mortality was $5.2 \%$. Overall survival at 10 years was $48.3 \pm 4.1 \%$ and freedom from cardiac death was 73.7 $\pm 5.4 \%$. At 10 years, freedom from hospital readmission for cardiac reasons was $54.6 \pm 3.9 \%$, freedom from thromboembolic events and/or major anticoagulation-related bleeding was $95.8 \pm 1.7 \%$, and freedom from reoperation was $94.4 \pm 1.3 \%$. Twenty patients developed acute bacterial endocarditis during the postoperative follow-up. These patients were excluded from further analysis of SVD.

\section{Patient-Prosthesis Mismatch}

The overall incidence of PPM was 53\%. The incidence in each valve type is listed in Table 1 . Forty-seven percent of the patients had an EOAi $>0.85 \mathrm{~cm}^{2} / \mathrm{m}^{2}, 49 \%$ had an EOAi between $0.85 \mathrm{~cm}^{2} / \mathrm{m}^{2}$ and $0.65 \mathrm{~cm}^{2} / \mathrm{m}^{2}$, and $4 \%$ had and EOAi $<0.65 \mathrm{~cm}^{2} / \mathrm{m}^{2}$. For further analysis, we considered a value $<0.85 \mathrm{~cm}^{2} / \mathrm{m}^{2}$ as PPM $(53 \%)$. Stentless valves had significantly less PPM (44 patients out of 199, 
or $22 \%$ ) than stented valves (301 out of 449 , or $67 \%$; $P<.0001)$. Patients having PPM had significantly higher peak gradients at discharge than patients not having PPM $(31.1 \pm 11.7 \mathrm{~mm} \mathrm{Hg}$ vs $21.3 \pm 8.5 \mathrm{~mm} \mathrm{Hg}, P<.0001)$.

\section{Structural Valve Degeneration}

The diagnosis of SVD was made in 73 patients $(12.6 \%)$. Forty-four patients had a stenotic valve (S-SVD; 7.6\%) and 29 patients had an incompetent valve (R-SVD; 5.0\%). Based on these echocardiographic criteria, freedom from SVD was substantially lower than that of reoperation (Figure 1). At 10 years, freedom from SVD was $81.0 \pm$ $2.4 \%$ whereas freedom from reoperation was $94.4 \pm$ $1.3 \%$. Stringent echocardiographic follow-up leads to (early) detection of SVD in a phase when reoperation is not required (yet).

In the univariate Cox analysis toward SVD and toward the 2 subtypes (S-SVD and R-SVD), the following variables revealed a $P$ value $<.1$ : (1) labeled valve size, EOAi, absence of anticalcification treatment, and presence of PPM for SVD and for S-SVD; and (2) labeled valve size, tissue origin, and absence of anticalcification treatment for R-SVD. These variables were inserted into the multivariable Cox models (Table 2). None of the patient-related variables proved to be significantly related to any of the SVD forms.

The multivariable Cox analysis revealed that absence of anticalcification treatment is an independent predictor of SVD, S-SVD, and R-SVD. Patient-prosthesis mismatch is an independent predictor of SVD and S-SVD, but not of R-SVD. Table 2 summarizes all $P$ values from the singlepredictor analysis, together with the hazard ratios resulting from the multivariable Cox analysis.

Patients receiving a nontreated valve show a freedom from SVD (all forms) at 10 years of follow-up of $70.1 \pm$ $4.3 \%$ versus $90.9 \pm 3.6 \%$ in patients receiving a treated valve (Figure $2, A ; P<.0001$ ). Valve treatment induces a significant delay of both S-SVD (Figure 2, $B$ ) and of R-SVD (Figure 2, C). Stenotic-type SVD starts to occur much earlier (at about 3-5 years) than R-SVD, which starts late (at about 9-10 years), but progresses quickly in the group having a nontreated valve (Figure $2, B$ and $C$ ). Figure 3 illustrates the effect of PPM on S-SVD, as we have demonstrated previously. ${ }^{1}$

\section{Additive Effect of Anticalcification Treatment and PPM}

The interaction between PPM and anticalcification treatment on the incidence of SVD is depicted in Figure 4. Patients having PPM and receiving a nontreated valve show a freedom of SVD at 10 years of follow-up of only 59.8 $\pm 7.0 \%$ versus $88.7 \pm 3.6 \%$ in patients having PPM but receiving a treated valve $(P<.0001)$. In patients not having PPM, the corresponding values were $78.0 \pm 4.3 \%$ and
$92.7 \pm 3.4 \%$ for nontreated versus treated valves, respectively $(P<.01)$.

\section{DISCUSSION}

The efficacy of antimineralization treatments of bioprosthetic heart valves has never been proved in a clinical setting. Although several of these antimineralization treatments are actually applied to clinically available tissue valves, clinical trials to show their efficacy were never required by health care authorities. The only evidence of efficacy is provided by experimental studies, including the accelerated calcification models in sheep. ${ }^{6,11-13}$ From clinical work, we know that the age of the recipient will determine the incidence of prosthetic valve degeneration. ${ }^{14,15}$ Experimental work was needed to show that factors such as the design-related stress distribution on the device, the origin of the tissue, the type of agent used to cross-link this tissue, and, last, the anticalcification treatment used during the preparation of the devices are all factors determining the calcification potential of these bioprosthetic valves. $6,11-13$

In this study, we included the following valves as nontreated prostheses: the Pericarbon and the Mitroflow (both Sorin, Saluggia, Italy) valve as stented bovine pericardial valves, the Labcor valve (Sulzer Carbomedics, Austin, Tex) as a stented porcine valve, and the Toronto SPV (St Jude Medical, St Paul, Minn) and the Prima (Edwards, Irvine, Calif) valves as stentless porcine prostheses. As treated valves, we included the Perimount valve (Edwards) as a stented pericardial valve, the Mosaic valve (Medtronic, Minneapolis, Minn) as a stented porcine valve, and the Freestyle valve (Medtronic) as a stentless porcine valve. This means that we accepted alpha-oleic acid as a treatment in the Mosaic and the Freestyle valves, and Tween- 80 as a treatment in the Perimount valve. ${ }^{6}$

Our current data suggest that antimineralization treatment of bioprosthetic heart valves is effective and reduces the onset and incidence of both forms of SVD significantly. Remarkable is that these treatments not only prevent or at least postpone prosthetic valve stenosis, but also can prevent valve regurgitation, most likely caused by cusp rupture. As Carpentier ${ }^{2}$ highlighted in his editorial comment on our previous work, the originality of our previous study ${ }^{1}$ relating PPM to SVD was in the distinction between 2 simple categories of valve structural deterioration (ie, S-SVD and R-SVD) and their relation to PPM. Indeed, not all bioprostheses showing SVD exhibit stenosis and calcification. Some valves show only rupture of the cusps, whereas others show the combination of leaflet calcification and rupture. ${ }^{16,17}$ Cusp ruptures were often associated with fatigue of the material; but, on the other hand, tears in the leaflets were also associated with micro- or macroscopic calcification of the tissue, which are possible causes of cusp ruptures. ${ }^{18,19}$ We classify bioprosthetic valves showing increasing pressure gradients 
TABLE 1. Descriptive data of the valve types included in the study

\begin{tabular}{|c|c|c|c|c|c|c|c|}
\hline Valve Type & $\mathbf{n}$ & Implant period & Design & Tissue origin & Treatment & Incidence PPM & Clinical FU (y) \\
\hline Mosaic & 148 & $1997-2003$ & Stented & Porcine & Treated & $67.6 \%$ & $7.1 \pm 2.9$ \\
\hline Pericarbon & 48 & 1993-1995 & Stented & Pericardial & Untreated & $70.8 \%$ & $7.3 \pm 4.3$ \\
\hline Perimount & 165 & $1995-2004$ & Stented & Pericardial & Treated & $61.8 \%$ & $7.7 \pm 2.0$ \\
\hline Labcor & 49 & $2000-2003$ & Stented & Porcine & Untreated & $85.7 \%$ & $6.0 \pm 2.6$ \\
\hline Mitroflow & 39 & 2000-2004 & Stented & Pericardial & Untreated & $58.9 \%$ & $6.1 \pm 2.9$ \\
\hline Toronto SPV & 85 & $1995-2002$ & Stentless & Porcine & Untreated & $23.5 \%$ & $8.7 \pm 2.9$ \\
\hline Freestyle & 64 & $1996-2005$ & Stentless & Porcine & Treated & $25.0 \%$ & $7.2 \pm 3.1$ \\
\hline Prima & 50 & 1991-1993 & Stentless & Porcine & Untreated & $18 \%$ & $9.4 \pm 3.7$ \\
\hline
\end{tabular}

PPM, Patient-prosthesis mismatch; $F U$, follow-up (mean \pm standard deviation); $C A B G$, concomitant coronary bypass grafting; $A H T$, hypertension; $D M$, treated diabetes mellitus; Chol, hypercholesterolemia; Obes, obesity (body mass index $>30$ ); Stat, statin use; $M S$, presence of metabolic syndrome (at least 3 of the previous 5 factors present); SPV, stentless porcine valve.

across the valve in combination with regurgitation as S-SVD. Valves demonstrating only valvular regurgitation are classified as R-SVD. To make this distinction, complete echocardiographic follow-up data, including pressure gradients across the valve, description of leaflet calcification, and semiquantitative indications of regurgitation, become mandatory to classify valve failure. It is clear that, only through stringent echocardiographic follow-up, an early detection of SVD is possible during a phase when reoperation is not required (yet). Too many clinical reports studying SVD use the (late) event of reoperation as the moment of (end-stage) SVD diagnosis.

The concept of PPM implies, as a main hemodynamic consequence, the generation of higher than expected gradients through normally functioning prosthetic valves. ${ }^{20}$ The incidence of moderate and severe PPM can vary substantially within published series, depending on valve types studied and used EOA reference values. ${ }^{21}$ High-pressure gradients at the outflow of the left ventricle can explain the association of PPM with less regression of left ventricular hypertrophy, more cardiac events, and lower survival,

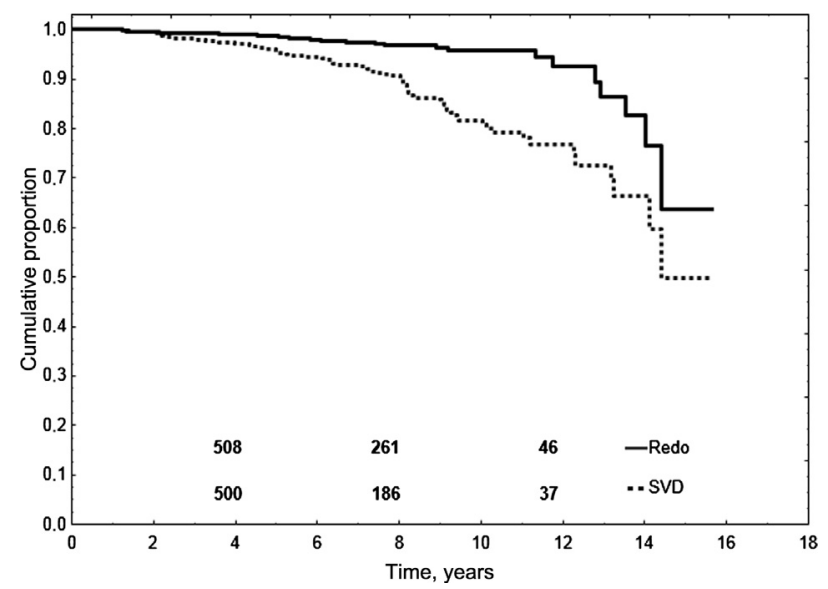

FIGURE 1. Freedom from reoperation (solid line) and SVD (dashed line). It is clear that stringent echocardiographic follow-up leads to detection of SVD in a phase when reoperation is not required (yet). Numbers at risk are shown at 4,8 , and 12 years. SVD, Structural valve degeneration; Redo, reoperation. as shown by Pibarot and Dumesnil. ${ }^{7}$ However, such a disturbance of hemodynamic flow patterns might also have an influence on the structural integrity of the prosthetic valve tissue and may result in the calcifying stenosis of the prosthesis that we find in our patients having PPM. We showed clearly that PPM is an independent predictor of S-SVD but not of R-SVD. On the other hand, we also showed that absence of treatment of bioprosthetic valves predicts a greater incidence of S-SVD and R-SVD. This finding suggests that alpha-oleic acid and Tween- 80 treatments protect not only against leaflet calcification, but also against leaflet matrix instability and rupture.

The clinical consequence of our findings is clear: Besides the prevention of PPM, the use of nontreated bioprosthetic heart valves should be avoided. Because valve type and size are determined at the moment of implantation, the surgeon carries an important responsibility in protecting the patient from valve degeneration.

\section{Study Limitations}

Structural valve degeneration is a nonfatal event. Its diagnosis and the time of detection depend highly on the frequency and completeness of echocardiographic followup within the patient cohort. In the analysis of these events,

TABLE 2. Statistical analysis

\begin{tabular}{|c|c|c|c|}
\hline Factor & SVD & $\begin{array}{l}\text { Stenotic-type } \\
\text { SVD }\end{array}$ & $\begin{array}{c}\text { Regurgitation-type } \\
\text { SVD }\end{array}$ \\
\hline Tissue origin & —* & —* & $\mathrm{NS} \dagger$ \\
\hline No treatment & $2.97(2.32-3.82)$ & $4.44(3.16-6.23)$ & $3.16(2.01-4.95)$ \\
\hline EOAi & $\mathrm{NS} \dagger$ & $\mathrm{NS} \dagger$ & —* \\
\hline PPM & $1.95(1.52-2.51)$ & $2.69(1.82-3.97)$ & —* \\
\hline Size & $\mathrm{NS} \dagger$ & $\mathrm{NS} \dagger$ & $\mathrm{NS} \dagger$ \\
\hline \multicolumn{4}{|c|}{$\begin{array}{l}\text { Multivariable analysis of SVD (all forms), stenotic-type and regurgitation-type SVD. } \\
\text { Analyzed factors included labeled valve size, EOAi, absence of anticalcification } \\
\text { treatment, and presence of PPM for SVD and for stenotic-type SVD; and labeled } \\
\text { valve size, tissue origin, and absence of anticalcification treatment for } \\
\text { regurgitation-type SVD. If the factor remained significant in the multivariable setting, } \\
\text { the resulting hazard ratio is shown with its } 95 \% \text { confidence interval. SVD, Structural } \\
\text { valve degeneration; } N S \text {, not significant; } E O A i \text {, effective orifice area index; } P P M \text {, } \\
\text { patient-prosthesis mismatch. *The factor was not analyzed within the multivariable } \\
\text { model given its nonsignificant univariate } P \text { value. †The factor was no longer signifi- } \\
\text { cant in the multivariable model. }\end{array}$} \\
\hline
\end{tabular}


TABLE 1. Continued

\begin{tabular}{|c|c|c|c|c|c|c|c|c|}
\hline Echo FU (y) & Male & CABG & AHT & DM & Chol & Obes & Stat & MS \\
\hline $6.0 \pm 3.4$ & $78(53 \%)$ & $82(55 \%)$ & $109(74 \%)$ & $21(14 \%)$ & $40(27 \%)$ & $30(20 \%)$ & $25(17 \%)$ & $16(11 \%)$ \\
\hline $5.5 \pm 3.8$ & $22(46 \%)$ & $41(83 \%)$ & $32(68 \%)$ & $7(15 \%)$ & $7(15 \%)$ & $3(6 \%)$ & $3(6 \%)$ & $3(6 \%)$ \\
\hline $5.6 \pm 3.3$ & $84(51 \%)$ & $72(44 \%)$ & $121(74 \%)$ & $24(15 \%)$ & $63(39 \%)$ & $24(15 \%)$ & $35(21 \%)$ & $18(11 \%)$ \\
\hline $5.5 \pm 2.7$ & $28(57 \%)$ & $27(53 \%)$ & $21(43 \%)$ & $5(10 \%)$ & $19(39 \%)$ & $6(12 \%)$ & $13(27 \%)$ & $3(6 \%)$ \\
\hline $6.0 \pm 2.9$ & $21(54 \%)$ & $20(51 \%)$ & $20(51 \%)$ & $5(13 \%)$ & $9(23 \%)$ & $3(8 \%)$ & $7(18 \%)$ & $1(3 \%)$ \\
\hline $7.9 \pm 3.1$ & $43(51 \%)$ & $45(52 \%)$ & $38(45 \%)$ & $11(13 \%)$ & $39(46 \%)$ & $11(13 \%)$ & $22(26 \%)$ & $9(11 \%)$ \\
\hline $7.0 \pm 3.6$ & $36(56 \%)$ & $25(39 \%)$ & $44(69 \%)$ & $14(22 \%)$ & $16(25 \%)$ & $14(22 \%)$ & $9(14 \%)$ & $9(14 \%)$ \\
\hline $7.3 \pm 3.7$ & $25(50 \%)$ & $0(0 \%)$ & $30(60 \%)$ & $4(8 \%)$ & $9(18 \%)$ & $4(8 \%)$ & $1(2 \%)$ & $1(2 \%)$ \\
\hline
\end{tabular}

ideally an interval-censored technique is used, with the time interval between the last echocardiographic follow-up demonstrating normal valve function and the first echocardiographic follow-up demonstrating SVD. In 2 previous studies, we did so and used the poor man's data augmentation multiple imputation method for interval censored data, according to Pan. ${ }^{1,22,23}$ In addition, the nonparametric
Turnbull estimate was used instead of Kaplan-Meier curves to create a graphic representation of the time to SVD. Post factum, however, no difference was shown between the outcome of these models in comparison with the regular Cox analysis and Kaplan-Meier estimates, which was most likely a result of the fact that our echocardiographic data were quite extensive and complete. In this series, even
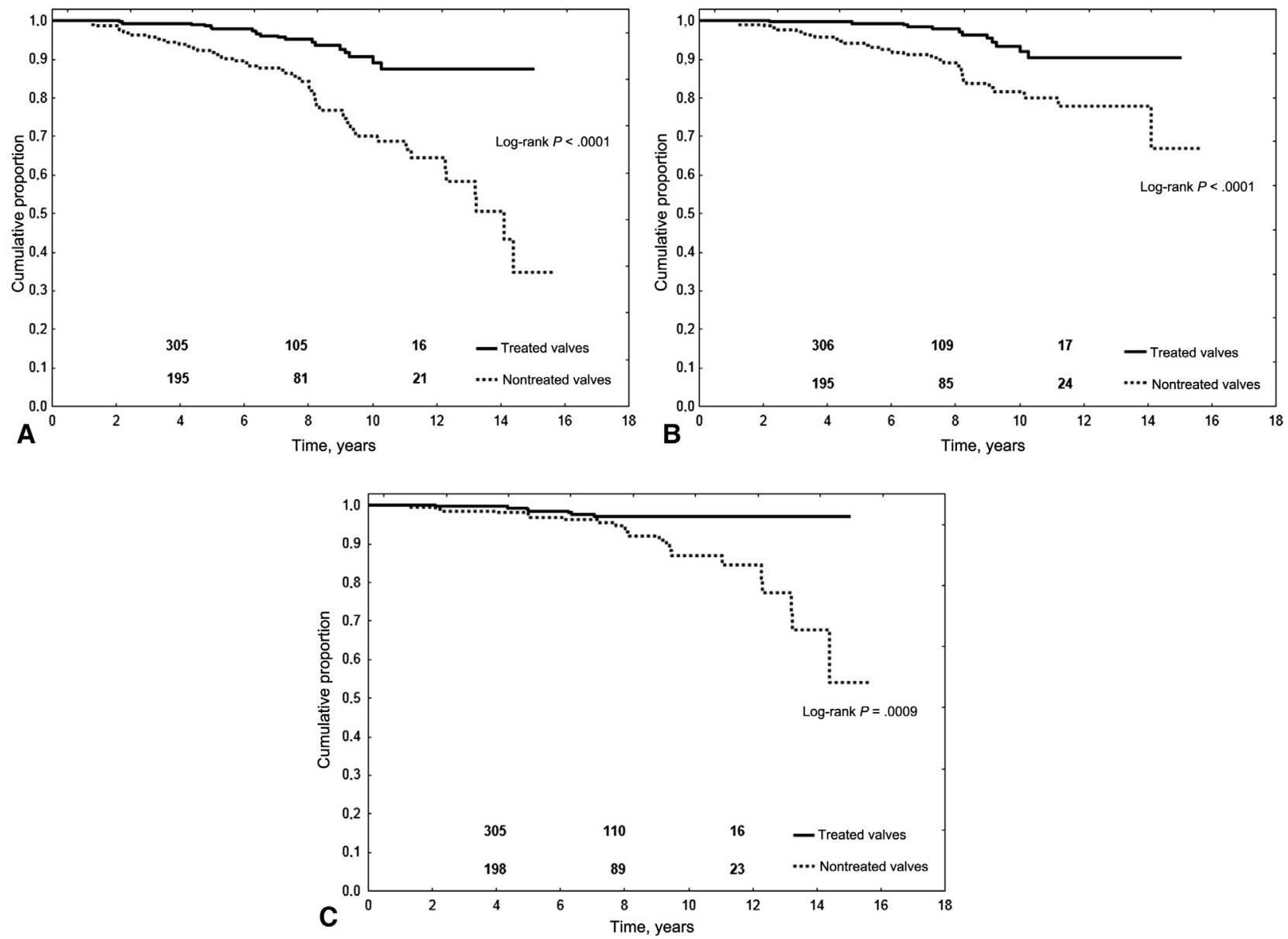

FIGURE 2. A, Freedom from SVD (all forms) in patients with a treated or a nontreated valve (log-rank $P<.0001)$. B, Freedom from stenotic-type SVD in patients with a treated or a nontreated valve $(\log$-rank $P<.0001)$. C, Freedom from regurgitation-type SVD in patients with a treated or a nontreated valve ( $\log$-rank $P=.0009)$. Numbers at risk are shown at 4,8 and 12 years. 


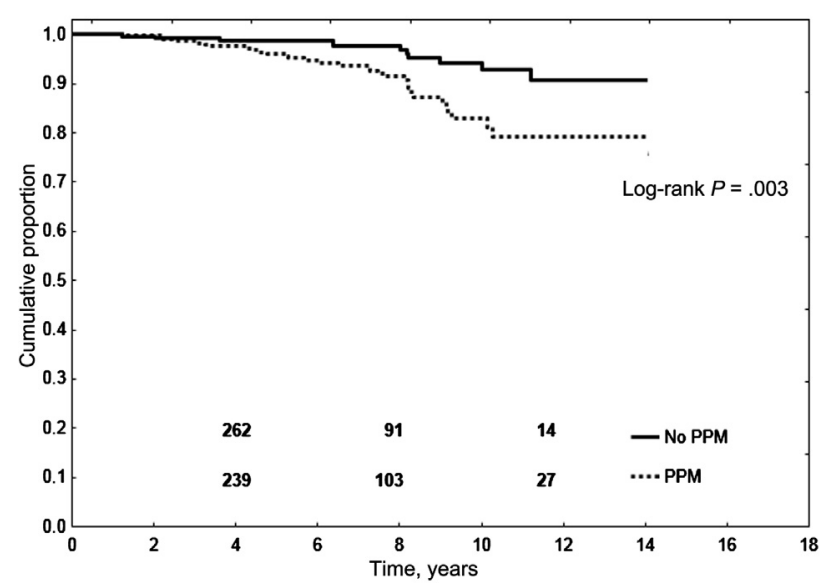

FIGURE 3. Freedom from stenotic-type SVD in patients with or without PPM (log-rank $P=.003)$. Numbers at risk are shown at 4,8 , and 12 years. $P P M$, Patient-prosthesis mismatch.

more echocardiographic data were collected, which led us to refrain from these "complex" and less familiar models and to use regular statistical methods. Throughout this study, peak gradients were used for the SVD diagnosis, because the incompleteness of mean transvalvular gradients and EOAi's inhibited their use in the analysis. We were unable to reveal an effect of patient-related variables on SVD, potentially because of the older mean age of our population and the relative low number of SVD events, compromising the power of the analysis. The low event rate also makes it

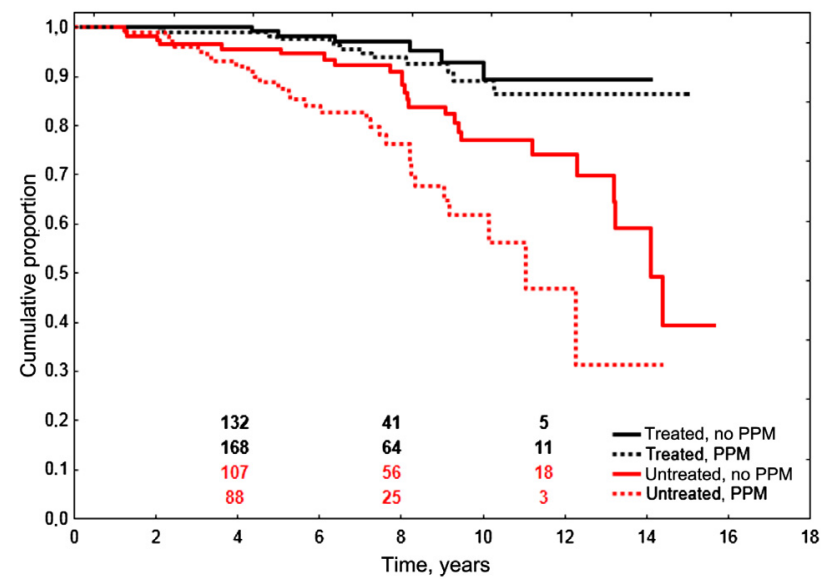

FIGURE 4. Additive effect of valve anticalcification treatment and PPM on freedom from SVD (all forms). Black curves represent treated valves; red curves represent untreated valves. Patients with PPM are represented with dashed lines. Patients having PPM and receiving an untreated valve show a freedom from SVD at 10 years of follow-up of only $59.8 \pm$ $7.0 \%$ versus $88.7 \pm 3.6 \%$ in patients having PPM but receiving a treated valve $(P<.0001)$. In patients not having PPM, the corresponding values were $78.0 \pm 4.3 \%$ and $92.7 \pm 3.4 \%$ for nontreated versus treated valves, respectively $(P<.01)$. Numbers at risk are shown at 4,8 , and 12 years. $P P M$, Patient-prosthesis mismatch. impossible to discriminate the effect of different types of antimineralization agents.

\section{References}

1. Flameng W, Herregods MC, Vercalsteren M, Herijgers P, Bogaerts K, Meuris B. Prosthesis-patient mismatch predicts structural valve degeneration in bioprosthetic heart valves. Circulation. 2010;121:2123-9.

2. Carpentier A. Hemodynamic factors affecting the fate of valvular bioprosthesis. Circulation. 2010;121:2083-4.

3. Rahimtoola SH. The year in valvular heart disease. J Am Coll Cardiol. 2011;58: 1197-207.

4. Rosenhek R. Almanac 2011: valvular heart disease: the national society journals present selected research that has driven recent advances in clinical cardiology. Heart. 2011;97:2007-17.

5. Yacoub MH, El-Hamamsy I. Valvular disease: the private life of tissue valves. Nat Rev Cardiol. 2010;7:424-6.

6. Flameng W, Meuris B, Yperman J, De VG, Herijgers P, Verbeken E. Factors influencing calcification of cardiac bioprostheses in adolescent sheep. J Thorac Cardiovasc Surg. 2006;132:89-98.

7. Pibarot P, Dumesnil JG. Hemodynamic and clinical impact of prosthesis-patient mismatch in the aortic valve position and its prevention. J Am Coll Cardiol. 2000; 36:1131-41.

8. Seguin JR, Grandmougin D, Folliguet T, Warembourg H, Laborde F, Chaptal PA. Long-term results with the Sorin Pericarbon valve in the aortic position: a multicenter study. J Heart Valve Dis. 1998;7:278-82.

9. Chambers J, Dolman W, Jawetz J, Ramos A, Collaco J, Barros-Pena J. An echocardiographic description of the Sulzer Carbomedics Synergy ST (Labcor) porcine valve in the aortic position. J Heart Valve Dis. 2000;9:661-6.

10. Akins CW, Miller DC, Turina MI, Kouchoukos NT, Blackstone EH, Grunkemeier GL, et al. Guidelines for reporting mortality and morbidity after cardiac valve interventions. J Thorac Cardiovasc Surg. 2008;135:732-8.

11. Barnhart GR, Jones M, Ishihara T, Chavez AM, Rose DM, Ferrans VJ. Failure of porcine aortic and bovine pericardial prosthetic valves: an experimental investigation in young sheep. Circulation. 1982;66:I150-3.

12. Jones M, Eidbo EE, Hilbert SL, Ferrans VJ, Clark RE. The effects of anticalcification treatments on bioprosthetic heart valves implanted in sheep. ASAIO Trans. 1988;34:1027-30.

13. Schoen FJ, Levy RJ, Hilbert SL, Bianco RW. Antimineralization treatments for bioprosthetic heart valves: assessment of efficacy and safety. $J$ Thorac Cardiovasc Surg. 1992;104:1285-8.

14. Hammermeister K, Sethi GK, Henderson WG, Grover FL, Oprian C, Rahimtoola SH. Outcomes 15 years after valve replacement with a mechanical versus a bioprosthetic valve: final report of the Veterans Affairs randomized trial. J Am Coll Cardiol. 2000;36:1152-8.

15. al-Khaja N, Belboul A, Rashid M, el-Gatit A, Roberts D, Larsson S, et al. The influence of age on the durability of Carpentier-Edwards biological valves: thirteen years follow-up. Eur J Cardiothorac Surg. 1991;5:635-40.

16. Jamieson WR, Burr LH, Janusz MT, Munro AI, Hayden RI, Miyagishima RT, et al. Carpentier-Edwards standard and supraannular porcine bioprostheses: comparison of technology. Ann Thorac Surg. 1999;67:10-7.

17. Kappetein AP, Takkenberg JJ, Puvimanasinghe JP, Jamieson WR, Eijkemans M, Bogers AJ. Does the type of biological valve affect patient outcome? Interact Cardiovasc Thorac Surg. 2006;5:398-402.

18. Goffin YA, Bartik MA. Porcine aortic versus bovine pericardial valves: a comparative study of unimplanted and from patient explanted bioprostheses. Life Support Syst. 1987;5:127-43.

19. Valente M, Bortolotti U, Arbustini E, Talenti E, Thiene G, Gallucci V. Glutaraldehyde-preserved porcine bioprosthesis: factors affecting performance as determined by pathologic studies. Chest. 1983;83:607-11.

20. Rahimtoola SH. The problem of valve prosthesis-patient mismatch. Circulation. 1978;58:20-4

21. Mohty D, Dumesnil JG, Echahidi N, Mathieu P, Dagenais F, Voisine P, et al. Impact of prosthesis-patient mismatch on long-term survival after aortic valve replacement: influence of age, obesity, and left ventricular dysfunction. $J \mathrm{Am}$ Coll Cardiol. 2009;53:39-47.

22. Pan W. A multiple imputation approach to Cox regression with interval-censored data. Biometrics. 2000;56:199-203.

23. Flameng W, Herijgers P, Bogaerts K. Recurrence of mitral valve regurgitation after mitral valve repair in degenerative valve disease. Circulation. 2003;107: 1609-13. 